\title{
Negative views of the mother after childhood sexual abuse
}

\author{
Janet D. Feigenbaum
}

In chllchood sexual cbuse cases, the non-cbusing parent (usually the mother) is often seen as colluder, helpless bystander or victim. These negative viows moy be based on misconceptions cbout incestuous families and con lead to treatiment bias and neglect of the other 'victims' of abuse. Mental heatth professionals and support agencies should ensure that the needs of the non-cbusing parent are met as well as those of the victim and perpetrator.

The 'cost' of childhood sexual abuse (CSA) to mental health services is great both in emotional and financial terms. Most interventions are geared towards the victim or the perpetrator, while the non-abusing parent and the siblings are given little if any support in dealing with the psychological and social consequences of abuse. Understanding the impact of abuse on other family members could lead to more effective and supportive interventions.

The mother ${ }^{1}$ is the family member most often neglected or maligned: "when daughters are abused, mothers are accused" (Johnson, 1992). People react by asking questions: How could a mother let this happen? How could she not know? Why didn't she protect her daughter?

The image of mothers of incest victims often accepted by professionals, police and the criminal justice system is frequently negattve. These mothers are often blamed for not protecting their children from trauma. implying that they are responsible for the incestuous activity between the abuser and child because of sexually depriving or rejecting their husbands. (Sirles \& Lofberg, 1990)

Kalichman et al (1990) looked at attributions of blame by professionals when confronted with cases of CSA. They found that when the father denied that the abuse had occurred, mothers were blamed more; the mother was viewed as a collaborator or responsible for not protecting her daughter. Such prejudice may prevent

1. Although this article will discuss the impact of father-daughter abuse, it is important to bear in mind that many of the issues are equally relevant to fatherson, mother-son and mother-daughter incestuous events. professionals from offering psychological support to the mother. Continuing trauma in the mother will have a detrimental effect on the recovery of the abused individual.

This paper will focus on the foundations of negative views of the mother, and the impact of these negative views on recovery for both victims and their families. Since there is little research in this area and much of this is based on small clinical samples, there is urgent need for further studies.

\section{Characteristics of the incestuous family}

Lack of understanding of the origins of incestuous families may lead society and professionals to hold negative views of mothers as "weak and ineffectual in the least damaging way or as hostile and dependent in the worse view" (Alexander, 1985).

Pelletier \& Handy (1986) suggest that there are three representative incestuous family types. In the possessive-passive family the father rules with complete authority, sometimes by force; is often described as "manipulative, impulstve, dominating, and unpredictable": and tends to marry immature or insecure women who can be kept emotionally and financially dependent. Such women are often unavailable for their children through emotional or physical disability. The second type of family is the marriage between a dependent man and a domineering woman (Furniss, 1983). These women tire of being "mother" to their husbands and withdraw from their spouses emotionally and sexually. Frequently these women are cold and rejecting of their children. They are often absent from the home and therefore unavailable to protect their children. The third type of family involves the union of a dependent man and a dependent woman, where neither is able to fulfil the other's overwhelming needs. Inadequate as parents and as spouses, they look to their children for parenting. All three types present mothers as either weak or absent.

These views are simplistic and harmful. It is important to recognise that mothers are 
members of a dynamic family unit struggling with a number of interpersonal roles and relationships. From a systems viewpoint any action on the part of one individual will have repercussions for all. Second, a significant number of mothers of CSA victims have themselves suffered abuse as children. As a result of intergenerational transmission of behaviour or inadequate personality development, some women may be unable to foresee, prevent or acknowledge abuse of their children.

\section{What happens to the mother after disclosure}

Very few studies have looked at the impact of disclosure on mothers (see Hooper, 1992; Johnson, 1992). While various services work with the abused daughter (and possibly with the perpetrator), the mother is often left to cope with her own emotions and difficulties while being encouraged to support her daughter and the remaining family members.

A common reaction to disclosure is for the mother to withdraw from her daughter. This may be due to remorse, guilt, self-blame, depression or even anger. She may be angry both with the perpetrator for abusing the daughter, and with her daughter for breaking up the family, for 'allowing the abuse to occur', or for revealing the secret. If the mother has herself been abused in the past, there may be feelings of anger which arise as a result of remembering her own abuse. There may also be considerable anger at the system' (e.g. the slowness of the legal system, the endless questioning by social services and the delays in receiving financial assistance). Feelings of responsibility for her daughter (Why didn't I protect her? How could I have not known?') may be accompanied by the thought 'I've been conned'. The mother may become depressed and grieve as a result of the numerous losses she will be experiencing (e.g. partner, family, financial support, social support and trust). Her self-esteem and confidence may be severely damaged since she views herself as a failure as mother, wife and woman.

\section{Relationship between mother and daughter}

When abuse is disclosed, the relationship between mother and daughter may undergo serlous difficulties as both come to terms with the meaning and impact of the abuse. Jacobs (1994) found that $60 \%$ of daughters had strong negative feelings towards their mothers. Much of the anger came after disclosure, depending upon how the mother reacted. Jacobs suggests that daughters often perceive their mothers as being inadequate. They feel violated and betrayed by their mothers for not fulfilling their role as protector. Often the victim is unable to see the possible reasons for the mother's 'failure'; biased professionals may encourage or perpetuate these beliefs.

Other features of the mother-daughter relationship described by victims include: emotional rigidity, feelings of distance, hostility or rejection from their mothers (Jacobs, 1994). Maternal emotional distance may arise from the mother's own history of abuse which prevents her from developing a close emotional relationship with her daughter, confusion about her dual feelings towards her partner and her daughter, or as a response to emotional manipulation by the father (for example, replacing the wife in bed may lead to feelings of jealousy, anger or inadequacy). Another explanation is that the victim's need for support, understanding and protection are great but she is unable to tell anyone about these needs, thus she perceives normal emotional support and understanding from the mother as inadequate (Jacobs, 1994).

\section{External views of mother}

Three common views of mother include mother as colluder, as helpless dependant, or as victim (Hooper, 1992; Johnson, 1992). The view of mother as colluder implies that the mother is aware of the sexual abuse of the daughter and chooses to ignore it, either to preserve her relationship with the father or for her own needs. In this sense the mother is thought to 'sacrifice the daughter'. She is believed to have condoned the abuse by turning away, and when confronted with disclosure disbelieves or blames her daughter.

However, mothers are not trained to recognise the symptoms of abuse. Failing to recognise the signs of abuse does not necessarily imply collusion. Second, incestuous families are characterised by poor intergenerational boundaries. isolation, inappropriate balance of power, and secrecy, thus the mothers may be 'overwhelmed' or 'oppressed' rather than colluding (de Young, 1994). Thirdly, mothers frequently have to deal with a great deal of conflict in their roles as mother and wife (de Young, 1994).

The second predominant view of mother is that of the helpless dependant, aware of what is happening but powerless to stop it. She may be overly dependent upon her husband and fears his withdrawal from the family; too depressed or infirmed to take a stand; economically unable to support the family; suffering from low selfesteem; or suffering from a personality disorder which prevents her from understanding or coping with the situation. Since domestic 
violence is often associated with incest, mothers may fear the physical consequences if they leave. In families where abuse is perpetrated by the stepfather the women are dealing with the added stigma of a previous falled marriage (see Johnson, 1992).

The third predominant view suggests that the mother is a victim of her own abuse. When confronted with the daughter's abuse, the mother relives the trauma of her own abuse and is so "overwhelmed and threatened by her own memories and emotions..." (Jacobs, 1994) that she is unable to accept or cope with her daughter's abuse.

All three attitudes are damaging to mother and family (Ringwalt \& Earp, 1988). Professionals' negative views lead to increasing self-blame and guilt which may lower self-esteem. The overwhelming psychological impact can lead to the onset or deepening of depression, alcohol or drug misuse, or even suicide. This may be because the mother is unable to cope with the high level of demands placed upon her by social services, legal cases, financial concerns and a disrupted social support network. Mothers may fear being condemned by the helping agencies and thus avoid seeking help. Professional anger at the mother for not protecting her daughter may inhibit work with the family. All of this increases the chances of mothers "keeping the secret" for yet another generation (Furniss, 1991).

However, professionals are not the only problem. Neighbours, teachers and others hold these same stereotyped negative images. Since the father has often worked to ensure that the family is isolated from the community and extended family, negative reactions leave the mother further cut off and unsupported within her impoverished social network.

The child may also be aware of negative reactions, which may increase the emotional conflict and distance between mother and daughter. The child may feel guilty and responsible for the difficulties the mother is having and blame themselves for the ostracism and poor treatment of the mother.

\section{Clinical implications}

Work with CSA often centres around the victim and the perpetrator, ignoring the needs of other family members. Acknowledging the needs of the mother can improve the mother-child relationship and so aid recovery. Psychological support for the mother should be offered early to help her to cope with the aftermath of abuse, including responding to the needs of the victim and/or her siblings, and organising the reconstruction of their lives. The clinician should avoid preconceptions and prejudice. Understanding the mother's own history will clarify issues which may need to be resolved in order for her to deal with the distress arising from the disclosure of abuse. Finally, one needs to focus on the relationship between the mother and the abused daughter. Unresolved issues may lead to feelings of anger, hurt, abandonment, resentment and misunderstanding. Improving communication between mother and daughter could help to resolve the emotional distress of both.

\section{Conclusions}

The consequences of childhood sexual abuse for the victim are well documented, but frequently the psychological impact on the mother (nonabusing parent) is overlooked. Fallure to respond to her needs may be due to pre-existing negative judgements. There is evidence that failure by professionals to provide a positive environment for disclosure, and lack of support for all family members, could lead to the family not disclosing and to the perpetuation of these patterns in the next generation.

\section{References}

ALEXANDER, P. C. (1985) A systems theory conceptualization of incest. Family Process, 24, 79-88.

DE Young. M. (1994) Women as mothers and wives in paternally incestous families: coping with role conflict. Child Abuse and Neglect, 18, 73-83.

FurNiss, T. (1983) Family process in the treatment of intrafamilial child sexual abuse. Joumal of Family Therapy. 5. 263-278.

- (1991) The Mult-Professional Handbook of Child Sexual Abuse: Integrated Management. Therapy. and Legal Intervention. London: Routledge.

Hooper. C. (1992) Mothers Surviving Child Sexual Abuse. London: Tavistock/Routledge.

JACOBS. J. L. (1994) Victimized Daughters: Incest and the Development of the Female Self. New York: Routledge.

Johnson, J. T. (1992) Mothers of Incest Survivors: Another Side of the Story. Indiana: Indiana University Press.

Kaluchman, S. C., Crang, M. E. \& Folungstad, D. R. (1990) Professionals' adherence to mandatory child abuse reporting laws: effects of responsibility. attribution. confidence ratings, and situational factors. Child Abuse and Neglect, 14, 69-77.

Peuetier, G. \& Handy, L. C. (1986) Family dysfunction and the psychological impact of child sexual abuse. Canadian Journal of Psychiatry. 31, 407-412.

RINGWALT, C. \& EARP, J. (1988) Attributing responsibility in cases of father-daughter sexual abuse. Child Abuse and Neglect. 12. 273-281.

SIRLES, E. A. \& LOFBERG, C. E. (1990) Factors associated with divorce in intrafamily child sexual abuse cases. Child Abuse and Neglect, 14, 165-170.

Janet D. Feigenbaum, Department of Psychology. Institute of Psychiatry. De Crespigny Park, Denmark Hill, London SE5 8AF 